\title{
The Effect of Cardiac Resynchronization on Morbidity and Mortality in Heart Failure
}

\author{
John G.F. Cleland, M.D., Jean-Claude Daubert, M.D., \\ Erland Erdmann, M.D., Nick Freemantle, Ph.D., Daniel Gras, M.D., \\ Lukas Kappenberger, M.D., and Luigi Tavazzi, M.D., \\ for the Cardiac Resynchronization — Heart Failure (CARE-HF) Study Investigators*
}

ABSTRACT

BACK GROU N D

Cardiac resynchronization reduces symptoms and improves left ventricular function in many patients with heart failure due to left ventricular systolic dysfunction and cardiac dyssynchrony. We evaluated its effects on morbidity and mortality.

\section{METHODS}

Patients with New York Heart Association class III or IV heart failure due to left ventricular systolic dysfunction and cardiac dyssynchrony who were receiving standard pharmacologic therapy were randomly assigned to receive medical therapy alone or with cardiac resynchronization. The primary end point was the time to death from any cause or an unplanned hospitalization for a major cardiovascular event. The principal secondary end point was death from any cause.

\section{RESULTS}

A total of 813 patients were enrolled and followed for a mean of 29.4 months. The primary end point was reached by 159 patients in the cardiac-resynchronization group, as compared with 224 patients in the medical-therapy group (39 percent vs. 55 percent; hazard ratio, $0.63 ; 95$ percent confidence interval, 0.51 to $0.77 ; \mathrm{P}<0.001$ ). There were 82 deaths in the cardiac-resynchronization group, as compared with 120 in the medical-therapy group ( 20 percent vs. 30 percent; hazard ratio 0.64 ; 95 percent confidence interval, 0.48 to $0.85 ; \mathrm{P}<0.002$ ). As compared with medical therapy, cardiac resynchronization reduced the interventricular mechanical delay, the end-systolic volume index, and the area of the mitral regurgitant jet; increased the left ventricular ejection fraction; and improved symptoms and the quality of life ( $\mathrm{P}<0.01$ for all comparisons).

\section{CONCLUSIONS}

In patients with heart failure and cardiac dyssynchrony, cardiac resynchronization improves symptoms and the quality of life and reduces complications and the risk of death. These benefits are in addition to those afforded by standard pharmacologic therapy. The implantation of a cardiac-resynchronization device should routinely be considered in such patients.
From the Department of Cardiology, Castle Hill Hospital, Kingston-upon-Hull, United Kingdom (J.G.F.C.); the Department of Cardiology, Hôpital Pontchaillou, Rennes, France (J.-C.D.); Klinik III für Innere Medizin der Universität zu Köln, Cologne, Germany (E.E.); the University of Birmingham, Edgbaston, United Kingdom (N.F.); Nouvelles Cliniques Nantaises, Nantes, France (D.G.); the Division of Cardiology, Centre Hospitalier Universitaire Vaudois, Lausanne, Switzerland (L.K.); and Istituto di Ricovero e Cura a Carattere Scientifico, Policlinico San Matteo, Pavia, Italy (L.T.). Address reprint requests to Dr. Cleland at the Department of Cardiology, Castle Hill Hospital, University of Hull, Kingston-uponHull, United Kingdom, or at j.g.cleland@ hull.ac.uk.

*The CARE-HF Study investigators are listed in the Appendix.

This article was published at www.nejm. org on March 7, 2004.

N Engl J Med 2005;352:1539-49.

Coppright $\odot 2005$ Massachusetts Medical Society. 


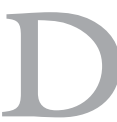

ESPITE IMPROVEMENTS IN PHARMAcologic treatment, many patients with heart failure have severe and persistent symptoms, and their prognosis remains poor. ${ }^{1,2}$ Such patients commonly have regions of delayed myocardial activation and contraction, leading to cardiac dyssynchrony. In a series of trials lasting up to six months, cardiac resynchronization decreased symptoms and improved exercise capacity, the quality of life, and ventricular function. ${ }^{3-7}$ The Comparison of Medical Therapy, Pacing, and Defibrillation in Heart Failure (COMPANION) trial showed that cardiac-resynchronization therapy alone or combined with an implantable defibrillator reduced the composite end point of death from any cause or hospitalization during a mean follow-up of 16 months $^{8}$; however, the decrease in the risk of death was not significant with cardiac resynchronization therapy alone $(\mathrm{P}=0.06)$. Meta-analyses have left lingering uncertainty about the effects of cardiac resynchronization on the risk of complications and death. ${ }^{9,10}$ We analyzed the effects of cardiac resynchronization on the risk of complications and death among patients who were receiving standard medical therapy for moderate or severe heart failure and cardiac dyssynchrony.

\section{METHODS}

The Cardiac Resynchronization - Heart Failure (CARE-HF) trial was a multicenter, international, randomized trial comparing the effect on the risk of complications and death of standard pharmacologic therapy alone with that of the combination of standard therapy and cardiac resynchronization (without a defibrillator) in patients with left ventricular systolic dysfunction, cardiac dyssynchrony, and symptomatic heart failure. ${ }^{11-13}$ Patients were enrolled at 82 European centers; enrollment began in January 2001 and ended in March 2003. The study was not blinded. The members of the end-points committee (see the Appendix), however, were not aware of patients' treatment assignments. Patients in the control group were not scheduled to receive a device, both for ethical reasons and so that the trial could assess the entire effect of cardiac resynchronization, including complications associated with implantation of the device. ${ }^{11-13}$

The steering committee (see the Appendix) designed the trial. The Medtronic Corporation funded the trial and provided a study manager to supervise its conduct. Data were sent by investigators to core laboratories or to an independent clinical-research organization (Quintiles, Dublin) that maintained the database, issued data-clarification forms, and assisted by Medtronic employees, verified source documents. The sponsor had no access to the database and did not participate in the analysis of the results or the writing of the article. All analyses were performed by one of the authors with the assistance of an independent statistician. Three Medtronic representatives commented on the manuscript before its submission. The study was approved by the local ethics committee of each participating institution and by appropriate national ethics committees. All patients provided written informed consent.

\section{PATIENTS}

Eligible patients were at least 18 years of age, had had heart failure for at least six weeks, and were in New York Heart Association (NYHA) class III or IV despite receipt of standard pharmacologic therapy, with a left ventricular ejection fraction of no more than 35 percent, a left ventricular end-diastolic dimension of at least $30 \mathrm{~mm}$ (indexed to height), and a QRS interval of at least $120 \mathrm{msec}$ on the electrocardiogram. Patients with a QRS interval of 120 to $149 \mathrm{msec}$ were required to meet two of three additional criteria for dyssynchrony: an aortic preejection delay of more than $140 \mathrm{msec}$, an interventricular mechanical delay of more than $40 \mathrm{msec}$, or delayed activation of the posterolateral left ventricular wall. ${ }^{11-13}$

Patients who had had a major cardiovascular event in the previous six weeks, those who had conventional indications for a pacemaker or an implantable defibrillator, and those with heart failure requiring continuous intravenous therapy were excluded. Also excluded were patients with atrial arrhythmias, since such patients cannot benefit from the atrial component of resynchronization. ${ }^{11-13}$

\section{STUDY PROCEDURES}

Randomization was stratified according to the NYHA class and was carried out by Quintiles with the use of a minimization procedure. Patients who were randomly assigned to undergo cardiac resynchronization received a Medtronic InSync or InSync III device, which provided atrial-based, biventricular stimulation with the use of standard right ventricular and Attain (Medtronic) left ventricular leads. Investigators were asked to position the left ventricular lead to pace the lateral or posterolateral left ventricular wall transvenously and provide radiographic documentation. Backup atrial pacing was set at 60 beats per minute. The interventricular delay was set 
to zero, and the atrioventricular delay was echocardiographically optimized. ${ }^{11}$ Patients were monitored overnight after receiving the device. If the initial procedure failed, repeated attempts at implantation were encouraged, and expert assistance was provided.

\section{FOLLOW-UP}

Patients were evaluated at $1,3,6,9,12$, and 18 months and every six months thereafter, and standard medications were adjusted as appropriate at these visits. Investigators were asked to report all adverse events, which were classified in a blinded fashion by an end-points committee or, if they were procedure-related or device-related, by an independent expert who was not blinded to the study-group assignments (see the Appendix).

The protocol required follow-up to continue for 18 months after the last patient had been enrolled, unless the data and safety monitoring board stopped the study earlier or fewer than 300 patients had reached a primary end point at that time, in which case the trial could be extended. On March 6, 2004, the board recommended extending the study until May 2005 without disclosing the reasons. However, since the prespecified criteria had been met, the steering committee decided to conclude the study as planned on September 30, 2004, ${ }^{11}$ and implemented, without knowledge of the results, an extension phase with death from any cause as the (nominal) primary outcome. On February 24, 2005, after this article had been submitted for publication, the data and safety monitoring board indicated that the main reasons for its recommendation were interim analyses showing a trend toward more cardiovascular events in the first 10 days after randomization among patients assigned to cardiac resynchronization than among those assigned to medical therapy alone and a trend toward a favorable effect of resynchronization on long-term mortality that they thought might fail to reach significance by the time of the planned closure date.

\section{END POINTS}

The primary end point was a composite of death from any cause or an unplanned hospitalization for a major cardiovascular event; only the first event in each patient was included in this analysis. Data on patients who underwent elective heart transplantation were censored seven days after the procedure. Emergency heart transplantation was counted as a death.
All hospitalizations were adjudicated in a blinded fashion by the end-points committee. The first hospitalization with documented worsening heart failure, myocardial infarction, unstable angina, arrhythmia, stroke, or other major cardiovascular event (e.g., pulmonary embolism or ruptured aortic aneurysm) or hospitalization owing to or prolonged by a serious procedure-related event (e.g., infection, pericardial hemorrhage, or tension pneumothorax) was counted in the primary end point. Hospitalization with worsening heart failure was defined by the occurrence of increasing symptoms and the need for treatment with intravenous diuretics or a substantial increase in oral diuretics (an increase of at least $40 \mathrm{mg}$ of furosemide per day, $1 \mathrm{mg}$ of bumetanide per day, or $10 \mathrm{mg}$ of torsemide per day) or the initiation of a combination of a thiazide and a loop diuretic.

Admissions for symptoms without a documented major cardiac event were not included in the primary end point, nor were readmissions for lead displacement, unless it precipitated a cardiac emergency, or admissions for initial implantation of the device, since this was part of the protocol. To prevent bias in favor of cardiac resynchronization, hospitalizations within 10 days after randomization in either group did not count toward the primary end point.

The principal secondary outcome was death from any cause, which was classified according to mode and cause. ${ }^{11}$ Other secondary end points included a composite of death from any cause and unplanned hospitalization with heart failure and, at 90 days, the NYHA class and the quality of life as assessed by the patient with the use of the Minnesota Living with Heart Failure questionnaire (scores can range from 0 to 105 , with higher scores reflecting a poorer quality of life) ${ }^{14,15}$ and the European Quality of Life-5 Dimensions (EuroQoL EQ-5D) instrument (scores can range from -0.594 to 1.000 , with lower numerical values indicating a poorer quality of life; negative scores are associated with a quality of life that is considered worse than death). ${ }^{16}$ Death was given a notional NYHA class of $\mathrm{V}$ for the analysis of changes in functional class. Several echocardiographic and biochemical variables were assessed in core laboratories, including the severity of cardiac dyssynchrony, ventricular function, mitral regurgitation, and $\mathrm{N}$-terminal pro-brain natriuretic peptide (Elecsys, Roche Diagnostics), at baseline and at the 3-month and 18-month follow-up visits. Differences from baseline in heart rate and blood pressure 
were also compared in the two groups at followup. ${ }^{11}$ No data other than NYHA class were imputed for patients who died.

\section{STATISTICAL ANALYSIS}

All prespecified analyses were conducted according to the intention-to-treat principle. $\mathrm{P}$ values other than for the primary end point are nominal. The study had a statistical power ${ }^{17}$ of 80 percent to identify a 14 percent relative reduction or a 5.7 percentage point reduction in the rate of events, given a conventional one-sided $\alpha$ value of 0.025 and a predicted number of 300 events. ${ }^{11}$ The time to an event was calculated according to the Kaplan-Meier method and analyzed with the use of Cox proportional-hazards models, which included baseline NYHA class as a covariate. ${ }^{18}$ Continuous data were analyzed with the use of mixed models, which included baseline variables as patient-level covariates and study centers as random effects. ${ }^{19}$ Dichotomous outcomes were analyzed with the use of nonlinear mixed models, which included the NYHA class as a patient-level covariate and study centers as random effects. The rates of adverse events were compared between groups by means of Fisher's exact test. Analyses were conducted with the use of SAS software (version 9.12, SAS Institute). The data and safety monitoring board conducted two planned interim analyses with the use of nonsymmetric stopping rules. ${ }^{20}$

\section{RESULTS}

A total of 404 patients were assigned to receive medical therapy alone and 409 to receive medical therapy plus cardiac resynchronization. The mean duration of follow-up was 29.4 months (range, 18.0 to 44.7). By the end of the study, the survival status of all patients was known, 383 patients had reached the primary end point, and 202 patients had died.

\section{STUDY POPULATION}

Baseline characteristics were similar in the two groups (Table 1). Patients had well-treated moderate or severe heart failure and major left ventricular systolic dysfunction. Only 43 percent were taking high doses of diuretics (defined as at least $80 \mathrm{mg}$ of furosemide, at least $2 \mathrm{mg}$ of bumetanide, or at least $20 \mathrm{mg}$ of torsemide). Beta-blockers were taken at some time during the study by 85 percent of the patients in the medical-therapy group and 84 percent of those in the cardiac-resynchronization group.
Implantation of a device was attempted in 404 of the 409 patients assigned to undergo cardiac resynchronization. One patient died before undergoing the procedure, and in four instances, the patient or investigator decided not to proceed. A cardiacresynchronization device was implanted and activated in 390 patients (95 percent), in 349 on the first attempt; the device was implanted a median of four days (interquartile range, two to seven) after randomization. The median duration of hospitalization for implantation was five days (interquartile range, two to eight). Before the device could be activated, six patients had an unplanned hospitalization for cardiovascular reasons that qualified as a primary end point. Eight patients assigned to undergo cardiac resynchronization had a device with an additional defibrillator function implanted during the study.

In the medical-therapy group, implantation of a cardiac-resynchronization device alone was attempted in 43 patients and implantation of a resynchronization device with a defibrillator was attempted in 23 patients (both approaches were attempted in 1 patient). The device was activated in 50 patients. In 10 instances, a device was successfully implanted but programmed to provide only standard pacemaker or defibrillator functions to avoid crossover. In five patients, the attempt at implantation was unsuccessful. The device was activated in 19 patients (5 percent) before they reached the primary end point. Eight of these patients subsequently reached a primary end point, six of whom died. Of 31 patients in whom the device was activated after they had reached the primary end point, 7 subsequently died.

\section{PRIMARY END POINT}

By the end of the study, the primary end point had been reached in 159 patients in the cardiac-resynchronization group, as compared with 224 patients who received medical therapy alone (39 percent vs. 55 percent; hazard ratio, 0.63 ; 95 percent confidence interval, 0.51 to $0.77 ; \mathrm{P}<0.001$ ) (Fig. $1 \mathrm{~A}$ and Table 2). There were 384 unplanned hospitalizations for a major cardiovascular event in the control group and 222 in the cardiac-resynchronization group. Death was the primary event in 74 patients, and hospitalization in 309. Prespecified subgroup analyses for the primary end point revealed no heterogeneity in the effect of cardiac resynchronization (Fig. 2). Twelve patients in the cardiac-resynchronization group and 10 in the medical-therapy group 


\begin{tabular}{|c|c|c|}
\hline Characteristic & $\begin{array}{l}\text { Medical Therapy Alone } \\
\text { ( } N=404)\end{array}$ & $\begin{array}{l}\text { Medical Therapy plus Cardiac } \\
\text { Resynchronization ( } N=409)\end{array}$ \\
\hline \multicolumn{3}{|l|}{ Age (yr) } \\
\hline Median & 66 & 67 \\
\hline Interquartile range & $59-72$ & $60-73$ \\
\hline Male sex (\%) & $293(73)$ & $304(74)$ \\
\hline NYHA class IV (\%) & $27(7)$ & $23(6)$ \\
\hline Dilated cardiomyopathy (\%) & $193(48)$ & $177(43)$ \\
\hline Ischemic heart disease (\%) & $144(36)$ & $165(40)$ \\
\hline Heart disease of other causes (\%) & $67(17)$ & $67(16)$ \\
\hline \multicolumn{3}{|l|}{ Heart rate (beats/min) } \\
\hline Median & 70 & 69 \\
\hline Interquartile range & $61-78$ & $60-78$ \\
\hline \multicolumn{3}{|l|}{ Systolic blood pressure (mm Hg) } \\
\hline Median & 110 & 110 \\
\hline Interquartile range & $100-125$ & $100-125$ \\
\hline \multicolumn{3}{|l|}{ Diastolic blood pressure ( $\mathrm{mm} \mathrm{Hg}$ ) } \\
\hline Median & 70 & 70 \\
\hline Interquartile range & $60-80$ & $60-79$ \\
\hline \multicolumn{3}{|l|}{$\mathrm{N}$-terminal pro-brain natriuretic peptide $(\mathrm{pg} / \mathrm{ml}) \dagger$} \\
\hline Median & 1806 & 1920 \\
\hline Interquartile range & 719-3949 & $744-4288$ \\
\hline \multicolumn{3}{|l|}{ Left ventricular ejection fraction (\%) } \\
\hline Median & 25 & 25 \\
\hline Interquartile range & $22-29$ & $21-29$ \\
\hline \multicolumn{3}{|l|}{ Left ventricular end-systolic volume index $\left(\mathrm{ml} / \mathrm{m}^{2}\right)$} \\
\hline Median & 117 & 121 \\
\hline Interquartile range & $94-147$ & $92-151$ \\
\hline \multicolumn{3}{|l|}{ QRS duration (msec) } \\
\hline Median & 160 & 160 \\
\hline Interquartile range & $152-180$ & $152-180$ \\
\hline \multicolumn{3}{|l|}{ Interventricular mechanical delay (msec) } \\
\hline Median & 50 & 49 \\
\hline Interquartile range & $30-66$ & $32-67$ \\
\hline \multicolumn{3}{|l|}{ Mitral-regurgitation areał } \\
\hline Median & 0.23 & 0.21 \\
\hline Interquartile range & $0.11-0.34$ & $0.12-0.33$ \\
\hline \multicolumn{3}{|l|}{ Glomerular filtration rate $\left(\mathrm{ml} / \mathrm{min} / 1.73 \mathrm{~m}^{2}\right)$} \\
\hline Median & 61 & 60 \\
\hline Interquartile range & $46-73$ & $46-73$ \\
\hline Use of an ACE inhibitor or angiotensin-receptor blocker (\%) & $383(95)$ & $387(95)$ \\
\hline Use of a beta-blocker (\%) & $298(74)$ & $288(70)$ \\
\hline Use of spironolactone (\%) & $238(59)$ & $219(54)$ \\
\hline Use of a high-dose loop diuretic (\%)』 & $177(44)$ & $175(43)$ \\
\hline Use of digoxin (\%) & $181(45)$ & $165(40)$ \\
\hline
\end{tabular}

* NYHA denotes New York Heart Association, and ACE angiotensin converting enzyme.

$\uparrow$ To convert values for $\mathrm{N}$-terminal pro-brain natriuretic peptide to picomoles per liter, divide by 8.457 .

$\uparrow$ The area was calculated as the area of the color-flow Doppler regurgitant jet divided by the area of the left atrium in systole, both in square centimeters.

\A high-dose loop diuretic consisted of furosemide at a dose of $80 \mathrm{mg}$ or more, bumetanide at a dose of $2 \mathrm{mg}$ or more, or torsemide at a dose of $20 \mathrm{mg}$ or more. 


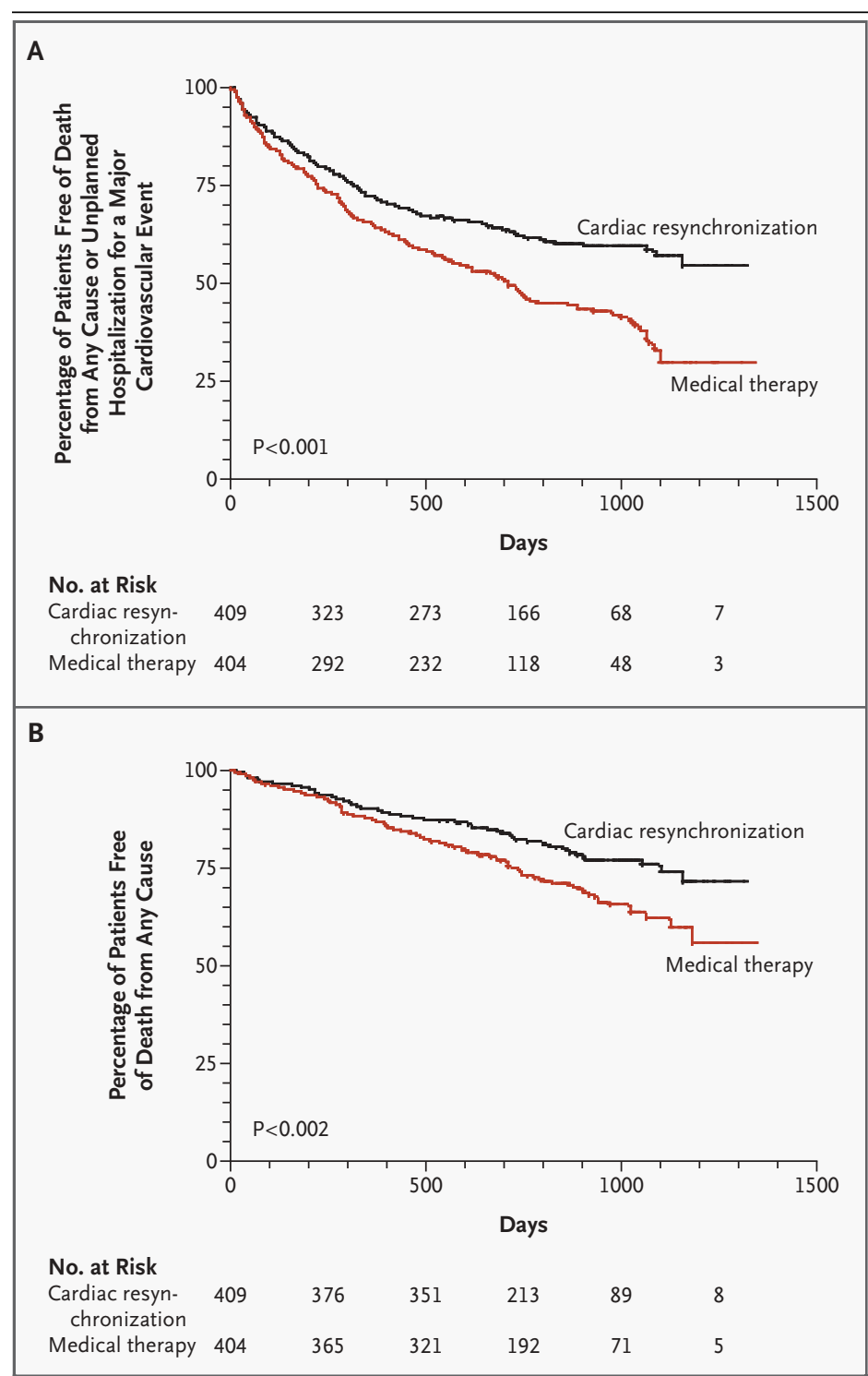

Figure 1. Kaplan-Meier Estimates of the Time to the Primary End Point (Panel A) and the Principal Secondary Outcome (Panel B).

The primary outcome was death from any cause or an unplanned hospitalization for a major cardiovascular event. The principal secondary outcome was death from any cause.

had unplanned hospitalizations for a major cardiovascular event that occurred within 10 days after randomization and were therefore not counted as primary end points.

\section{DEATHS}

In the cardiac-resynchronization group, 82 patients died, as compared with 120 patients who had been assigned to medical therapy alone (20 percent vs.
30 percent; hazard ratio, 0.64 ; 95 percent confidence interval, 0.48 to $0.85 ; \mathrm{P}<0.002$ ) (Fig. $1 \mathrm{~B}$ and Table 2). The principal cause of death was cardiovascular in 167 patients (83 percent), noncardiovascular in 34 patients (17 percent), and not classifiable in 1 patient ( 0.5 percent). The cause of death was attributed to worsening heart failure in 56 of the 120 patients who died in the medical-therapy group ( 47 percent) and in 33 of the 82 patients who died in the cardiac-resynchronization group (40 percent). The mode of death was classified as sudden in 38 of the 120 patients who died in the medicaltherapy group (32 percent) and in 29 of the $82 \mathrm{pa}-$ tients who died in the cardiac-resynchronization group (35 percent). The mortality rate in the medical-therapy group was 12.6 percent at one year and 25.1 percent at two years, as compared with 9.7 percent and 18.0 percent, respectively, in the cardiacresynchronization group.

There were three emergency and six elective heart transplantations in the medical-therapy group and one emergency and nine elective heart transplantations in the cardiac-resynchronization group. All the patients who underwent emergency heart transplantation died. None of the patients who underwent elective transplantation had died within seven days after transplantation, at which point their follow-up data were censored from the analysis.

\section{OTHER SECONDARY END POINTS}

As compared with medical therapy alone, cardiac resynchronization reduced the risk of the composite end point of death from any cause or hospitalization for worsening heart failure (hazard ratio, 0.54; 95 percent confidence interval, 0.43 to $0.68 ; \mathrm{P}<0.001$ ) (Table 2). There were 252 hospitalizations for worsening heart failure among 133 patients in the medical-therapy group (33 percent) and 122 such hospitalizations among 72 patients in the cardiacresynchronization group (18 percent).

As compared with patients in the medical-therapy group, patients in the cardiac-resynchronization group had less severe symptoms $(\mathrm{P}<0.001)$ and a better quality of life $(\mathrm{P}<0.001)$ at 90 days (Table 2$)$. At 90 days, 15 patients had died in the medical-therapy group and 12 patients had died in the cardiacresynchronization group. At 18 months, 105 of the patients in the cardiac-resynchronization group were in NYHA class I, 150 were in NYHA class II, and 80 were in NYHA class III or IV; the respective values in the medical-therapy group were 39,112 , and 152. 


\begin{tabular}{|c|c|c|c|c|}
\hline Outcome & $\begin{array}{l}\text { Medical Therapy } \\
\text { Alone } \\
(\mathrm{N}=404)\end{array}$ & $\begin{array}{c}\text { Medical Therapy plus } \\
\text { Cardiac Resynchronization } \\
\text { (N=409) }\end{array}$ & $\begin{array}{l}\text { Hazard Ratio } \\
\text { (95\% CI) }\end{array}$ & $P$ Value \\
\hline \multicolumn{5}{|c|}{ no. of patients (\%) } \\
\hline \multicolumn{5}{|l|}{ Primary outcome } \\
\hline $\begin{array}{l}\text { Death or unplanned hospitaliza- } \\
\text { tion for a cardiovascular event }\end{array}$ & $224(55)$ & 159 (39) & 0.63 (0.51 to 0.77 ) & $<0.001$ \\
\hline $\begin{array}{l}\text { Unplanned hospitalization for a } \\
\text { cardiovascular event } \dagger^{\dagger}\end{array}$ & $184(46)$ & $125(31)$ & 0.61 (0.49 to 0.77$)$ & $<0.001$ \\
\hline \multicolumn{5}{|l|}{ Secondary outcome } \\
\hline Death from any cause & $120(30)$ & $82(20)$ & 0.64 (0.48 to 0.85$)$ & $<0.002$ \\
\hline $\begin{array}{l}\text { Death from any cause or un- } \\
\text { planned hospitalization } \\
\text { with worsening heart failure }\end{array}$ & $191(47)$ & $118(29)$ & 0.54 (0.43 to 0.68$)$ & $<0.001$ \\
\hline \multirow{2}{*}{$\begin{array}{l}\text { Unplanned hospitalization with } \\
\text { worsening heart failure } \dagger\end{array}$} & $133(33)$ & $72(18)$ & 0.48 (0.36 to 0.64$)$ & $<0.001$ \\
\hline & $\begin{array}{l}\text { Medical Therapy } \\
\text { Alone } \\
(\mathrm{N}=404)\end{array}$ & $\begin{array}{c}\text { Medical Therapy plus } \\
\text { Cardiac Resynchronization } \\
\text { (N=409) }\end{array}$ & $\begin{array}{l}\text { Difference in Means } \\
\qquad(95 \% \mathrm{Cl}) \div\end{array}$ & $P$ Value \\
\hline \multicolumn{5}{|c|}{ value at 90 days } \\
\hline \multicolumn{5}{|l|}{ Continuous outcome } \\
\hline NYHA class & $2.7 \pm 0.9$ & $2.1 \pm 1.0$ & 0.6 (0.4 to 0.7$)$ & $<0.001$ \\
\hline $\begin{array}{l}\text { Minnesota Living with Heart } \\
\text { Failure score } \mathbb{}\end{array}$ & $40 \pm 22$ & $31 \pm 22$ & $-10(-8$ to -12$)$ & $<0.001$ \\
\hline EuroQoL EQ-5D score & $0.63 \pm 0.29$ & $0.70 \pm 0.28$ & 0.08 (0.04 to 0.12$)$ & $<0.001$ \\
\hline
\end{tabular}

* Plus-minus values are means \pm SD. The analysis was adjusted according to study center. NYHA denotes New York Heart Association, and $\mathrm{Cl}$ confidence interval.

$\dagger$ These events contributed to the primary or secondary outcome.

The difference shown is for the cardiac-resynchronization group as compared with the medical-therapy group.

$\int$ Scores on the Minnesota Living with Heart Failure questionnaire range from 0 to 105, with higher scores reflecting a poorer quality of life.

9 Scores on the European Quality of Life-5 Dimensions (EuroQoL EQ-5D) instrument range from -0.594 to 1.000, with 1.000 indicating fully healthy and 0 dead.

ECHOCARDIOGRAPHIC, BIOCHEMICAL, AND HEMODYNAMIC ASSESSMENTS

At both 3 months and 18 months, the left ventricular ejection fraction was significantly greater, the left ventricular end-systolic volume index was significantly lower, the area of mitral regurgitation was significantly smaller, and the interventricular mechanical delay was significantly shorter in the cardiac-resynchronization group than in the medicaltherapy group (Table 3). By 18 months, plasma levels of $\mathrm{N}$-terminal pro-brain natriuretic peptide were lower among patients in the cardiac-resynchronization group (Table 3). Systolic blood pressure was higher at both 3 months and 18 months among patients in the cardiac-resynchronization group.

\section{SERIOUS ADVERSE EVENTS}

There was one device-related death in each group: one patient in the cardiac-resynchronization group died of heart failure aggravated by lead displacement, and one patient in the medical-therapy group died of septicemia after receiving a device. The most common adverse device- or procedure-related events in the cardiac-resynchronization group were lead displacement (24 patients), coronary-sinus dissection (10 patients), pocket erosion (8 patients), pneumothorax ( 6 patients), and device-related infection (3 patients). Worsening heart failure was more common in the medical-therapy group (affecting 263 patients, as compared with 191 patients in the cardiac-resynchronization group; $\mathrm{P}<0.001$ ), whereas atrial arrhythmias or ectopy was more com- 
mon in the cardiac-resynchronization group (affecting 64 patients in that group, as compared with 41 in the medical-therapy group; $\mathrm{P}=0.02$ ). The frequencies of respiratory tract infections, hypotension, falls or syncope, acute coronary syndromes, renal dysfunction, ventricular arrhythmias or ectopy, and neurologic events were similar in the two groups.

\section{DISCUSSION}

We found that cardiac resynchronization substantially reduced the risk of complications and death among patients with moderate or severe heart failure owing to left ventricular systolic dysfunction and cardiac dyssynchrony. The benefits were similar among patients with ischemic heart disease and patients without ischemic heart disease and were in addition to those afforded by pharmacologic therapy. The data are consistent with a resynchronizationinduced reduction in cardiac dyssynchrony, leading to a sustained increase in left ventricular performance and a diminution of mitral regurgitation and, in turn, a rise in perfusion pressure, a fall in cardiac filling pressure, and favorable left ventricular remodeling. These changes in function translate into improvements in well-being and decreases in symptoms, complications, and the risk of death.

The favorable effects of cardiac resynchronization on symptoms, the quality of life, ventricular function, and blood pressure in our trial are similar to those reported in previous trials. ${ }^{4-8}$ However, we also found that cardiac resynchronization significantly reduced the risk of death. Calculations based on hazard ratios suggest that, for every nine devices implanted, one death and three hospitalizations for major cardiovascular events are prevented. This effect is in addition to the benefits of pharmacologic therapy and is similar to the reduction in the risk of death associated with beta-blocker therapy as compared with placebo in a similar population. ${ }^{21}$

The benefit of cardiac resynchronization therapy in our study was due, at least in part, to the adherence of patients and investigators to the protocol and to the increasing effect of cardiac resynchronization over a long follow-up period, but it was not due to the recruitment of patients at higher risk for events than those in other studies. Indeed, the mortality rate was lower than that in many other studies, possibly reflecting the high standard of care, the presence of less severe heart failure, or both. ${ }^{22-24}$
Figure 2 (facing page). Effect of Cardiac Resynchronization on the Primary End Point in Predefined Subgroups. Hazard ratios and 95 percent confidence intervals (Cls) are shown. The subgroups of age, systolic blood pressure, mitral-regurgitation area (as defined in Table 1), interventricular mechanical delay, ejection fraction, endsystolic volume index, and glomerular filtration rate are divided according to the median value in the study population. All analyses were stratified according to the NYHA class, except the subgroup analysis of NYHA class. To convert values for $\mathrm{N}$-terminal probrain natriuretic peptide (NT-BNP) to picomoles per liter, divide by 8.457 . For some data (QRS width, for instance), many patients had results at the median value, and this led to some inequality in the sizes of the subgroups. Because of missing baseline data, not all subgroup numbers total 813 .

The extent to which risk can be modified may be greater among patients with less severe disease. Cardiac resynchronization may be beneficial in patients with cardiac dyssynchrony even if their symptoms are not severe, although we excluded patients judged by the investigator to be in NYHA class I or II.

The hazard ratio for death among patients with a cardiac-resynchronization device, as compared with those receiving medical therapy alone $(0.64$; 95 percent confidence interval, 0.48 to 0.85 ; $\mathrm{P}<0.002$ ), was similar to that among patients who received both a resynchronization device and a defibrillator, as compared with medical therapy alone, in the COMPANION trial $(0.64$; 95 percent confidence interval, 0.48 to $0.86 ; \mathrm{P}=0.003) .{ }^{8}$ The COMPANION trial was not designed to investigate differences between the use of a cardiac-resynchronization device alone and the combination of a resynchronization device and an implantable defibrillator, but much of the effect of the latter approach could be explained by the cardiac-resynchronization component. In our study, the cardiac-resynchronization group had a decreased incidence of sudden death and a decreased incidence of death from worsening heart failure, both of which may reflect an improvement in cardiac function. A defibrillator might further reduce the risk of sudden death. ${ }^{25,26}$ Twenty-nine patients (7 percent) in the cardiac-resynchronization group died suddenly.

Retarding the progression of cardiac dysfunction to prevent malignant arrhythmias may be a better strategy than treating malignant arrhythmias once they occur, because defibrillation is stressful to the patient and associated with an adverse prognosis, 


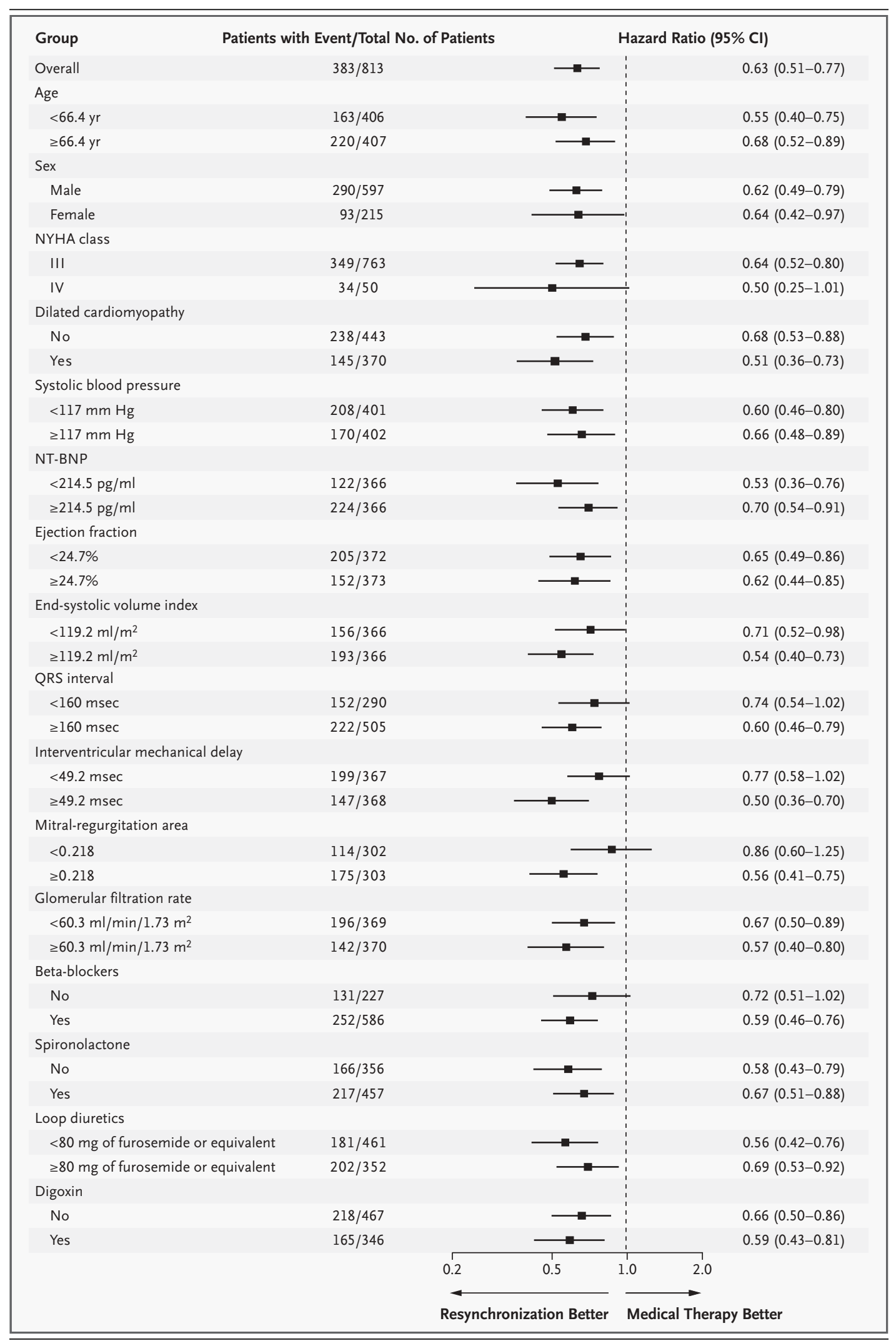




\begin{tabular}{|c|c|c|c|c|}
\hline Variable & $\begin{array}{l}\text { Difference in Means } \\
\text { at } 3 \mathrm{Mo}(95 \% \mathrm{Cl})\end{array}$ & $P$ Value & $\begin{array}{l}\text { Difference in Means } \\
\text { at } 18 \mathrm{Mo}(95 \% \mathrm{Cl})\end{array}$ & P Value \\
\hline Heart rate (beats/min) & $+1.1(-1.2$ to 3.4$)$ & 0.33 & $+1.0(-1.5$ to 3.6$)$ & 0.43 \\
\hline Systolic blood pressure $(\mathrm{mm} \mathrm{Hg})$ & $+5.8(3.5$ to 8.2$)$ & $<0.001$ & $+6.3(3.6$ to 8.9$)$ & $<0.001$ \\
\hline Diastolic blood pressure $(\mathrm{mm} \mathrm{Hg})$ & $+1.5(0.1$ to 2.9$)$ & 0.03 & $+1.3(-1.8$ to 4.4$)$ & 0.42 \\
\hline Interventricular mechanical delay (msec) & $-21(-25$ to -18$)$ & $<0.001$ & $-21(-25$ to -17$)$ & $<0.001$ \\
\hline Left ventricular ejection fraction (\%) & $+3.7(3.0$ to 4.4$)$ & $<0.001$ & $+6.9(5.6$ to 8.1$)$ & $<0.001$ \\
\hline $\begin{array}{l}\text { Left ventricular end-systolic volume } \\
\text { index }\left(\mathrm{ml} / \mathrm{m}^{2}\right)\end{array}$ & $-18.2(-21.2$ to -15.1$)$ & $<0.001$ & $-26.0(-31.5$ to -20.4$)$ & $<0.001$ \\
\hline Mitral-regurgitation area $\uparrow$ & $-0.051(-0.073$ to -0.028$)$ & $<0.001$ & $-0.042(-0.070$ to -0.014$)$ & 0.003 \\
\hline $\begin{array}{l}\text { N-terminal pro-brain natriuretic peptide } \\
\qquad(\mathrm{pg} / \mathrm{ml}) \ddagger\end{array}$ & $-225(-705$ to 255$)$ & 0.36 & $-1122(-1815$ to -429$)$ & $<0.002$ \\
\hline
\end{tabular}

* Differences were not adjusted for the higher mortality rate in the medical-therapy group. A plus sign indicates a greater value, and a minus sign a smaller value, in the cardiac-resynchronization group than in the medical-therapy group. $\mathrm{Cl}$ denotes confidence interval.

$\dagger$ The area was calculated as the area of the color-flow Doppler regurgitant jet divided by the area of the left atrium in systole, both in square centimeters.

$\lceil$ To convert the values for $\mathrm{N}$-terminal pro-brain natriuretic peptide to picomoles per liter, divide by 8.457 .

owing either to the cause of the arrhythmia or to the effects of the shock. ${ }^{27}$ Assuming that the combination of a cardiac-resynchronization device and a defibrillator could prevent two thirds of sudden deaths, a future study would require 1300 patients per group and a follow-up period similar to ours to have a statistical power of 90 percent to detect an absolute reduction in the risk of death from any cause of 5 percent with the use of combination therapy, as compared with the use of cardiac resynchronization alone.

In summary, we found that cardiac resynchronization is an effective therapy for patients with left ventricular systolic dysfunction and cardiac dyssynchrony who have moderate or severe heart failure and who are in sinus rhythm.

Supported by a grant from Medtronic.

Dr. Cleland reports having served as a consultant for Medtronic, Amgen, Menarini, and Pfizer and having received speakers' honoraria from Medtronic, Takeda, AstraZeneca, and Pfizer and grant support from the Medical Research Council (United Kingdom),
Hull and East Yorkshire Cardiac Trust, Medtronic, Vasomedical, and Abbott. Dr. Daubert reports having served as a consultant for and having received speakers' honoraria from Medtronic and St. Jude Medical. Dr. Erdmann reports having served as a consultant for and having received speakers' honoraria from Takeda, Merck (Darmstadt), Medtronic, and Guidant. Dr. Freemantle reports having served as a consultant for Medtronic and Pfizer and having received speakers' honoraria from Medtronic and grant support from Medtronic, Aventis, Amgen (United Kingdom), and the British Heart Foundation. Dr. Gras reports having served as a consultant for and having received speakers' honoraria from Medtronic and Guidant. Dr. Kappenberger reports having served as a consultant for Medtronic, having received speakers' honoraria from Medtronic, Biotronik, and Guidant, and having received grant support from Medtronic and the Swiss National Foundation for Scientific Research, Commission for Technology and Innovation/Kommission für Technologie und Innovation, and the Swiss Heart Foundation. Dr. Tavazzi reports having served as a consultant for Medtronic, Menarini, Servier, and Pfizer and having received speakers' honoraria from Medtronic, Novartis, and Takeda.

This article is dedicated to the memory of Werner Klein, professor of cardiology at the University Hospital of Graz (Austria), a member of the steering committee who died in 2004. He contributed substantially to the design and conduct of the study but did not live to see it completed. His wise counsel is greatly missed by his colleagues.

A P PENDIX

The following persons participated in the CARE-HF Study: Steering Committee - J.G.F. Cleland (chair), J.-C. Daubert, E. Erdmann, D. Gras, L. Kappenberger, W. Klein, L. Tavazzi; Data and Safety Monitoring Board - P.A. Poole-Wilson, L. Rydén (chair), H. Wedel, H.J.J. Wellens; End-Points Committee — B. Uretsky, K. Thygesen; Independent Device-Related Adverse-Event Assessor — D. Böcker; Study Management - M.M.H. Marijianowski; Statistical Analysis - N. Freemantle, M.J. Calvert; Pharmacologic Vigilance and Data Management - Quintiles; Investigators - Austria: G. Christ, F. Fruhwald, R. Hofmann, A. Krypta, F. Leisch, R. Pacher, F. Rauscha; Belgium: R. Tavernier; Denmark: P.E. Bloch Thomsen, S. Boesgaard, H. Eiskjær, G.T. Esperen, J. Haarbo, A. Hagemann, E. Korup, M. Mфller, P. Mortensen, P. Søgaard, T. Vesterlund; Finland: H. Huikuri, K.I. Niemelä, L. Toivonen; France: F. Bauer, A. Cohen-Solal, C. Crocq, P. Djiane, J.L. DuboisRande, P. de Groote, Y. Juilliere, G. Kirkorian, M. Komajda, T. Laperche, H. Le Marec, C. Leclercq, C. Tribouilloy; Germany: F. Er, E. Fleck, U.C. Hoppe, F.X. Kleber, B. Maisch, J. Neuzner, C. Reithmann, T. Remp, C. Schmitt, C. Stahl, R.H. Strasser; Italy: M.C. Albanese, A. Bartoloni, M. Bocchiardo, A. Capucci, A. Carboni, A. Circo, M. Disertori, R. del Medico, T. Forzani, M. Frigerio, A. Gavazzi, M. Landolina, M. 
Lunati, S. Mangiameli, M. Piacenti, A. Pitì, P.A. Ravazzi, A. Raviele, M. Santini, A. Serio, G.P. Trevi, M. Volterrani, M. Zardini; the Netherlands: F.A.L.E. Bracke, C.C. de Cock, A. Meijer, R. Tukkie; Spain: J. Casares Mediavilla, M. Concha, J.F. Delgado, A. González-García, R. MuñozAguilera, J. Martínez Ferrer, F. Ridocci; Sweden: B. Andren, J. Brandt, P. Blomström, M. Edner, K. Hellström, S. Jensen, B. Kristensson, F. Maru, S.J. Moller, F. Rönn, P. Smedgård, G. Wikström; Switzerland: J. Fuhrer, G. Girod; United Kingdom: G.H. Broomes, S. Chalil, H. Dargie, W. Davies, A. Delaney, P. Elliott, G.K. Goode, G. Haywood, G.C. Kaye, A.S. Kurbaan, R. Lane, T. Levy, F. Leyva, H. Marshall, S. Muhyaldeen, N. Nitikin, M.J.D. Roberts, J.D. Skehan, W.D. Toff, D.J. Wright; Core Echocardiography Laboratory (Pavia, Italy) - C. Bassi, S. Ghio, E. Ghizzardi, G. Magrini, M. Pasotti, V. Pierota, E. Tellaroli, A. Serio, L. Scelsi; Core Neuroendocrine Laboratory (Graz, Austria) - A. Fahrleitner, G. Leb, H. Wenisch; Therapy Delivery (Kingston-upon-Hull, United Kingdom) — A. Bennett, M. Cooklin, J. Ghosh, S. Hurren, G.C. Kaye, N.K. Khan.

\section{REFERENCES}

1. Khand A, Gemmel I, Clark AL, Cleland JGF. Is the prognosis of heart failure improving? J Am Coll Cardiol 2000;36:2284-6. 2. Cleland JGF, Clark AL. Delivering the cumulative benefits of triple therapy to improve outcomes in heart failure: too many cooks will spoil the broth. J Am Coll Cardiol 2003;42:1234-7.

3. Rogers JG, Cain ME. Electromechanica associations. N Engl J Med 2004;350:2193-5.

4. Cazeau S, Leclercq $C$, Lavergne $T$, et al Effects of multisite biventricular pacing in patients with heart failure and intraventricular conduction delay. N Engl J Med 2001; 344:873-80.

5. Young JB, Abraham WT, Smith AL, et al Combined cardiac resynchronization and implantable cardioversion defibrillation in advanced chronic heart failure: the MIRACLE ICD Trial. JAMA 2003;289:2685-94.

6. Abraham WT, Fisher WG, Smith AL, etal. Cardiac resynchronization in chronic heart failure. N Engl J Med 2002;346:1845-53.

7. Higgins SL, Hummel JD, Niazi IK, et al Cardiac resynchronization therapy for the treatment of heart failure in patients with intraventricular conduction delay and malignant ventricular tachyarrhythmias. J Am Coll Cardiol 2003;42:1454-9.

8. Bristow MR, Saxon LA, Boehmer J, et al. Cardiac-resynchronization therapy with o without an implantable defibrillator in advanced chronic heart failure. $\mathrm{N}$ Engl J Med 2004;350:2140-50.

9. McAlister FA, Ezekowitz JA, Wiebe N, et al. Systematic review: cardiac resynchronization in patients with symptomatic hear failure. Ann Intern Med 2004;141:381-90. [Erratum, Ann Intern Med 2005;142:311.]
10. Calvert M, Freemantle N, Cleland JG. Cardiac resynchronization therapy in heart failure. Ann Intern Med 2005;142:305-7. 11. Cleland JGF, Daubert JC, Erdmann E, et al. The CARE-HF study (Cardiac Resynchronisation in Heart Failure study): rationale, design and end-points. Eur J Heart Fail 2001;3:481-9.

12. Calvert MJ, Freemantle N, Cleland JGF The impact of chronic heart failure on health-related quality of life data acquired in the baseline phase of the CARE-HF study. Eur J Heart Fail 2005;7:243-51.

13. Cleland JGF, Daubert JC, Erdmann E, et al. Baseline characteristics of patients recruited into the CARE-HF study. Eur J Hear Fail 2005;7:205-14.

14. Rector TS, Tschumperlin LK, Kubo SH et al. Use of the Living With Heart Failure questionnaire to ascertain patients' perspectives on improvement in quality of life versus risk of drug-induced death. J Card Fail 1995;1:201-6.

15. Rector TS, Kubo SH, Cohn JN. Validity of the Minnesota Living with Heart Failure questionnaire as a measure of therapeutic response to enalapril or placebo. Am J Cardiol 1993;71:1106-7.

16. Brooks R. EuroQol: the current state of play. Health Policy 1996;37:53-72.

17. Shih JH. Sample size calculation for complex clinical trials with survival endpoints. Control Clin Trials 1995;16:395-407. 18. Collett D. Modelling survival data in medical research. London: Chapman \& Hall, 1994

19. McCulloch CE, Searle SR. Generalized, inear, and mixed models. New York: John Wiley, 2001.
20. Lan KKG, DeMets DL. Discrete sequential boundaries for clinical trials. Biometrik 1983;70:659-63.

21. CIBIS-II Investigators and Committee. The Cardiac Insufficiency Bisoprolol Study II (CIBIS-II): a randomised trial. Lancet 1999;353:9-13.

22. Packer M, Coats AJS, Fowler MB, et al Effect of carvedilol on survival in severe chronic heart failure. N Engl J Med 2001; 344:1651-8.

23. The CONSENSUS Trial Study Group. Effects of enalapril on mortality in severe congestive heart failure: results of the Cooperative North Scandinavian Enalapril Survival Study (CONSENSUS). N Engl J Med 1987; 316:1429-35.

24. Pitt B, Zannad F, Remme WJ, et al. The effect of spironolactone on morbidity and mortality in patients with severe heart failure. N Engl J Med 1999;341:709-17.

25. Bardy GH, Lee KL, Mark DB, et al. Amiodarone or an implantable cardioverter-defibrillator for congestive heart failure. N Engl J Med 2005;352:225-37.

26. Cleland JGF, Ghosh J, Freemantle N, et al. Clinical trials update and cumulative meta-analyses from the American College of Cardiology: WATCH, SCD-HeFT, DINAMIT, CASINO, INSPIRE, STRATUS-US, RIO-Lipids and cardiac resynchronisation therapy in heart failure. Eur J Heart Fail 2004;6:501-8. 27. Moss AJ, Greenberg H, Case RB, et al. Long-term clinical course of patients after termination of ventricular tachyarrhythmia by an implanted defibrillator. Circulation 2004;110:3760-5.

Copyright (c) 2005 Massachusetts Medical Society. 